\title{
Seismic Vulnerability Analysis of RC Buildings in Western China
}

\author{
Zhu Jian \\ Ning Xia University \\ China
}

\section{Introduction}

Kobe earthquake in Japan (Ms6.9) happened in 1995 Jan 17 at five o'clock in the morning, depth of the seismic focus was $20 \mathrm{~km}$, the seismic characteristic was shallow vertical focus earthquake, peak acceleration was 813 gal, predominant period was $0.3 \sim 0.5 \mathrm{~s}$, The main sediments of the region under 20 30 meters were sandy silt, and Generally to moderately weathered rock. 18 thousand buildings were been damaged and 1.2 thousand buildings were collapsed, half timber houses which built before 1980'were destroyed seriously, at the same time middle-storey reinforced-concrete (RC) buildings which were 7 8 layer buildings damaged also seriously, the mainly damage showing was integral overthrow of buildings, in addition columns between third to forth layer of RC buildings were squashed in the earthquake, and were collapsed in the middle of structures.

Tohoku Earthquake (Ms9.0) in Japan occurred on March,11 2011, it is regarded as the most devastating killer earthquake after the 1923 great kanto earthquake in Japan, in which almost 30000 people were killed or missed in the earthquake and the subsequent monster tsunami. The maximum height of the tsunami is reported to have been almost $40 \mathrm{~m}$. The recorded maximum peak ground acceleration was 2933 gal and large long-period wave components were recorded in Tokyo during the 2011 off the Pacific coast of Tohoku Earthquake. It is remarkable in this earthquake that the number of collapsed or damaged buildings and houses remains unclear because most of the damage resulted from the tsunami (Takewaki,2011).

Northridge earthquake(Ms 6.7) happened in 1994 Jan 17 at five o'clock in the morning, this is terrible earthquake with tremendous horizontal and vertical acceleration evenly to reach $1.0 \mathrm{~g}, 2500$ houses were been collapsed and 4000 houses were been damaged seriously by powerful natural energy, the main characteristic of buildings' damage was shear failure of columns in old second to third layer timberwork apartment blocks, and RC frames were damaged very small include several 40 layer high-rise RC buildings.

Taiwan Chichi earthquake (Ms7.6) happened in 1999 Sep 21 at one o'clock in the morning, depth of the seismic focus was $8 \mathrm{~km}$, and the earthquake was powerful shallow focus earthquake, damaged data of 8733 buildings were collected post earthquake, one to three layer RC buildings were damaged seriously, or about 52.5 percent, among which old RC buildings built before 1982 based insufficient seismic design and outdated seismic code were destroyed deeply, and occupied about 59.4 percent. Small high-rise shear-wall RC buildings were damaged tiny, and which occupied 6.4 percent. 
China Wenchuan earthquake(Ms8.0) happened in 2008 May 12 at two o'clock in the afternoon, in the seismic region are three main geological fault zones, and the Wenchuan earthquake occurred in Longmenshan (LMS) geological fault zone, total length of LMS is 530 kilometer $(\mathrm{km})$, width of which is $40 \sim 50 \mathrm{~km}$, presenting northeast-southwest running, and leaning to northwest about 30 70 angles, LMS divided into two parts by Jiangyou(JY) city in Sichuan province, northeast part of which is geological fault zone during Early Pleistocene-middle Middle Pleistocene, southwest part of which is fault zone during Holocene, the earthquake was happened in southwest part, depth of the seismic focus was $14 \mathrm{~km}$, and fracture length was $240 \mathrm{~km}$, the process of fracture consisted of several continuous events, every event was a earthquake which magnitude was Ms7.2 to Ms7.6, all type of buildings were damaged overlying in the continuous vibration, the peak acceleration recorded was 957.8gal, waves diffused all directions in three-dimensional, at the same time vibration along northeast of fracture zone was more powerfully, and continued for about 100 seconds, spreading to 16 provinces of China, specialists from State Seismological Bureau of China surveyed 500 thousand square kilometer, and in where 2419 square kilometer earthquake intensity reached 11 scale, far surpass design intensity in the region where is 7 scale.

In the Wenchuan earthquake, 5.46 million buildings were collapsed, number of serous damaged buildings were 5.93 million, amount to total damaged buildings exceeded 15 million, old brick masonry structures built 70 s $~ 80$ s damaged most seriously, in the next place low-rise RC buildings destroyed also severely, which were integral overthrow of base layer columns yielded because of wrong site, low material strength and fault layout. With Indian plate moving to north continuously and squeezing Asian plate, in the near future there is still high risk of major earthquake happen again in western China region, so how to evaluate reliability and vulnerability of the lifeline systems for future earthquake in the area and search reasonable design practice of seismic strengthening of these buildings is urgent mission.

\section{Summarize methods of structural seismic vulnerability analysis}

Damage from earthquake is comprehensive, there are different ways for various damage of engineering, seismic technician classify the vulnerability assessment as four sorts: empirical, judgmental, experimental and analytical according to whether the damage data used in their generation derives mainly from observed post-earthquake surveys, expert opinion, analytical simulations or combinations of these respectively.

As described below, the seismic vulnerability assessment of buildings at large geographical scales has been first carried out in the early 70 's, through the employment of empirical methods initially developed and calibrated as a function of macro-seismic intensities. This came as a result of the fact that, at the time, hazard maps were, in their vast majority, defined in terms of these discrete damage scales (earlier attempts to correlate intensity to physical quantities, such as PGA, led to unacceptably large scatter). Therefore these empirical approaches constituted the only reasonable and possible approaches that could be initially employed in seismic risk analyses at a large scale.

(Whitman, 1973) first proposed the use of damage probability matrices for the probabilistic prediction of damage to buildings from earthquakes. The concept of a DPM is that a given 
structural typology will have the same probability of being in a given damage state for a given earthquake intensity. The format of the DPM was suggested by (Whitman, 1973), where example proportions of buildings with a given level of structural and non-structural damage are provided as a function of intensity (note that the damage ratio represents the ratio of cost of repair to cost of replacement). (Whitman, 1973) compiled DPMs for various structural typologies according to the damaged sustained in over 1600 buildings after the 1971 San Fernando earthquake.

One of the first European versions of a damage probability matrix was produced by (Braga et al., 1982), which was based on the damage data of Italian buildings after the 1980 Irpinia earthquake, and this introduced the binomial distribution to describe the damage distributions of any class for different seismic intensities. The binomial distribution has the advantage of needing one parameter only which ranges between 0 and 1. On the other hand it has the disadvantage of having both mean and standard deviation depending on this unique parameter. The buildings were separated into three vulnerability classes (A, B and C) and a DPM based on the MSK scale was evaluated for each class. This type of method has also been termed 'direct' (Corsanego \& Petrini, 1990) because there is a direct relationship between the building typology and observed damage. The use of DPMs is still popular in Italy and proposals have recently been made to update the original DPMs of Braga. (Di Pasquale, 2005) have changed the DPMs from the MSK scale to the MCS (Mercalli-Cancani-Sieberg) scale because the Italian seismic catalogue is mainly based on this intensity, and the number of buildings has been replaced by the number of dwellings so that the matrices could be used in conjunction with the 1991 Italian National Statistical Office (ISTAT) data. (Dolce,2003) have also adapted the original matrices as part of the ENSeRVES (European Network on Seismic Risk, Vulnerability and Earthquake Scenarios) project for the town of Potenza, Italy. An additional vulnerability class D has been included, (Grüntal, 1998) using the EMS98 scale to account for the buildings that have been constructed since 1980. These buildings should have a lower vulnerability as they have either been retrofitted or designed to comply with recent seismic codes.

Judgmental method was based structural damage data can be considered the greatest cause of life and monetary loss in the majority of seismic events, vulnerability curves were been received under-predict the damage observed in buildings after earthquake, for example: Miyakoshi et al. [6] used damage data observed in RC buildings after the Kobe earthquake (Japan, 1995) in constructing damage parameter equation, (Yamazaki \& Murao, 2000) also made up of empirical vulnerability curve though analyzing damage data observed in buildings after the Kobe earthquake, (Orsini et al.,1999) used the Parameterless Scale of Intensity (PSI) ground-motion parameter to derive vulnerability curves for apartment units in Italy. Both studies subsequently converted the PSI to PGA using empirical correlation functions, such that the input and the response were not defined using the same parameter.

The use of observed damage data to predict the future effects of earthquakes also has the advantage that when the damage probability matrices are applied to regions with similar characteristics, a realistic indication of the expected damage should result and many uncertainties are inherently accounted for. However, there are various disadvantages associated with the continued use of empirical methods: 
1. A macro-seismic intensity scale is defined by considering the observed damage of the building stock and thus in a loss model both the ground motion input and the vulnerability are based on the observed damage due to earthquakes.

2. The derivation of empirical vulnerability functions requires the collection of postearthquake building damage statistics at sites with similar ground conditions for a wide range of ground motions: this will often mean that the statistics from multiple earthquake events need to be combined. In addition, large magnitude earthquakes occur relatively infrequently near densely populated areas and so the data available tends to be clustered around the low damage/ground motion end of the matrix thus limiting the statistical validity of the high damage/ground motion end of the matrix.

3. The use of empirical vulnerability definitions in evaluating retrofit options or in accounting for construction changes (that take place after the earthquakes on which those are based) cannot be explicitly modeled; however simplifications are possible, such as upgrading the building stock to a lower vulnerability class.

4. Seismic hazard maps are now defined in terms of PGA (or spectral ordinates) and thus PGA needs to be related to intensity; however, the uncertainty in this equation is frequently ignored. When the vulnerability is to be defined directly in terms of PGA, where recordings of the level of the ground shaking at the site of damage are not available, it might be necessary to predict the ground shaking at the site using a ground motion prediction equation; however, again the uncertainty in this equation needs to be accounted for in some way, especially the component related to spatial variability.

5. When PGA is used in the derivation of empirically-defined vulnerability, the relationship between the frequency content of the ground motions and the period of vibration of the buildings is not taken into account.

Laboratory testing represents the third alternative tool for vulnerability assessment. The main advantage of this method is the freedom in selecting model to suite the application. However, this method is hampered by the limitations of scale, laboratory and equipments capacities. Another factor affecting the reliability of this tool is the effect of loading type and routine on the response. Furthermore, the deficiency in modeling soil-structure interactions represents one of the main disadvantages of using the laboratory testing as a seismic vulnerability assessment tool. Pseudo dynamic testing has been used in several studies. However, the slow rate of testing represents a main obstacle in using this type of testing for vulnerability assessment where large sets of data points are required to make a comprehensive assessment. Recently sub-structuring and distributed testing have been used in different studies.

The last tool is analysis vulnerability method. The method has received much attention from researchers in recent years. Many researchers of countries such as (M.A.Erberik, 2004), (Rossetto. T, 2005), (S. Kircil,2006), (Jun Ji,2007) and (Barbara Borzi,2008) have studied seismic characteristic and vulnerability of many kinds of structures like reinforced concrete buildings, masonry buildings, bridges, museums and dams. Analysis offers two main advantages: the ease of controlling the level of refinement and feasibility of parametric studies. However, results of recent studies emphasized several issues that need to be resolved in order to enhance the use of analysis in realistic vulnerability assessment, including influence level between different models, ground vibration importing selecting, comprehensive structures analysis and computing consume. So analysis method is selected based all four tools characteristic, and the analysis tool will be used in classic RC buildings of western region in China in connecting fielding damage data observed after Wenchuan earthquake (2008) in China. 


\section{Response spectrum fitting stochastic artificial waves}

Probability response spectrum is an elastic response spectrum, which is enough as external load for most sample and general layout buildings of seismic design, but which is not suitable for comprehensive and lifeline structures, so nonlinear dynamic analysis is very necessary and importable to the lifeline structures. In fact, actual earthquake recorded waves are not easy for attainable in engineering research, and why is the reason how to use spectrum density and design response spectrum for fitting artificial stochastic seismic waves.

\subsection{Analysis procedure}

Artificial seismic waves analysis methods could be divided into engineering simulation method and seismology simulation method. Earthquake focus also be divided into many element focus in seismology simulation method, and which element focus excite site vibration in using theoretical or experimental ways, that in the end gathering site vibration by total element focus and to move forward to construct site seismic function. Engineering simulation method is made up appropriate seismic function in accordance with seismic Fourier frequency spectrum, energy spectrum density and response spectrum, engineering method has been accepted by engineering technician because of well academic foundation. So engineering simulation method is been selected in Matlab7.0 programming and simulate and fit artificial seismic stochastic waves according with design response spectrum. Five steps are following:

1. initial setting artificial seismic waves;

2. compute response spectrum of artificial seismic waves;

3. compare initial response spectrum with target response spectrum and compute both ratio;

4. regulate artificial seismic waves on the base of response ratio;

5. repeat step 2 and degree of fitting satisfy demand.

\subsection{Artificial seismic waves simulation}

There are three methods for artificial waves: tri-angle series method, stochastic impulse method and natural regression method, the third ways raised in 1970s, but the first method is accepted widely.

We suppose that an zero mean value $(E[x(t)=0])$ steady state diffuse scattering wave shape time history is $x(t)$, which may be showed by Fourier analysis, as shown in Eq.(1):

$$
x(t)=\sum_{k} A_{k} \exp \left[i\left(\omega_{k} t+\phi_{k}\right)\right]
$$

Where $\omega_{k}=k \Delta \omega, \Delta \omega=2 \pi / T_{d}, T_{d}$ is seismic time history, $A_{k}=A\left(\omega_{k}\right)$ is Fourier amplitude spectrum value, $\phi_{k}$ is phase angle, so we can decided $A_{k}, \phi_{k}$ according with vibration characteristic value, in other word, we can create steady vibration time history based above function. In which $\phi_{k}$ is created by random phase way and random range from 0 to $2 \pi$, certainly it my also take from real earthquake recorded waves. Frequency of vibration could shown by spectrum density function $S_{\ddot{X} g}(\omega)$, and $S(\omega)$ has relation with $A\left(\omega_{k}\right)$, $E\left[x(t)^{2}\right]=\int_{-\infty}^{\infty} S(\omega) d \omega=\sum_{k} A_{k}{ }^{2}$, mean $S\left(\omega_{k}\right) \Delta \omega=\frac{A_{k}{ }^{2}}{2}$, mean also $A_{k}=\left[2 S\left(\omega_{k}\right) \Delta \omega\right]^{\frac{1}{2}}$. 
In the mean time (Kaul, 1978) computed relation energy spectrum density function with response spectrum on the base of diffuse scattering theory shown as Eq. (2):

$$
S\left(\omega_{k}\right)=\frac{\left[\zeta / \pi \omega_{k}\right] S_{a}^{2}\left(\omega_{k}, \zeta\right)}{\operatorname{In}\left[\omega_{k} T_{d} /-\pi \operatorname{In}(1-p)\right]}
$$

Where $S_{a}$ is accelerate response spectrum, $\zeta$ is system damping ratio and initial setting as $5 \%, p$ is surpass probability and setting as $10 \%, T_{d}$ is time history 30 seconds, initial steady artificial seismic time history are shown by programmed with Matlab 7.0 in Fig.1:

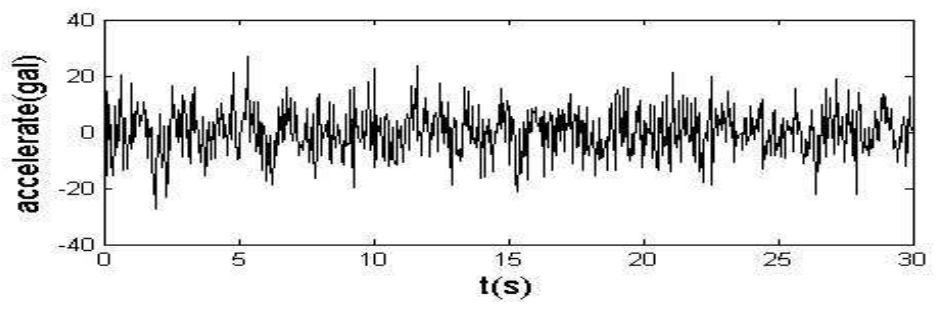

Fig. 1. Initial steady artificial vibration time history

Real earthquake wave is not an sample steady vibration, in consideration of initial vibration phase, main vibration phase and decline phase, so artificial waves only shown more accurately as stationary time history, in present, common way is steady state $x(t)$ multiply by decided time varying envelop function $g(t)$, that is to say, change stationary state into steady form.

Seismic acceleration could be shown as:

$$
A_{g}(t)=g(t) \ddot{X}_{g}(t)
$$

Where $\ddot{X}_{g}(t)$ is $x(t), g(t)$ is envelop curve, so structure of spectrum frequency is not vary with time but variance is changing with time.

Generally envelop function is decided in according with seismic total duration and strong vibration duration. Seismic total duration means earthquake time history from begin time to end time, we can know that seismic duration change from several seconds to dozens of seconds and at most one to two minutes, (Murphy and O'Brien,1977) from American analysis about 400 recorded earthquake waves and found the vast majority of recorded waves duration within $25 \sim 40$ s when the total duration within 2 100s, so 30s was decided as standard artificial wave duration. After engineering technician analyze vast actual seismic recorded acceleration $a(t)$, they found an common characteristic: stationary of intensity and frequency spectrum, vibration intensity divided as ascent stage, strong vibration sustain stage and weakening stage, meanwhile stationary in every stage. In engineering we often pay attention to strong vibration stage called strong vibration duration $T_{\alpha}$, because importance of strong vibration duration has been realized by engineering technician, but definition of which is not definite, so in the article relative duration based 
energy was been considered, and (Husid,1974), (Trifunac \& Bardy,1975) studied that they thought using $\int_{0}^{t} a^{2}(t) d t$ as time-vary characteristic of earthquake vibration energy, and shown as Eq.(4):

$$
I(t)=\frac{\int_{0}^{t} a^{2}(t) d t}{\int_{0}^{T} a^{2}(t) d t}
$$

Where $\mathrm{T}$ is total duration of seismic wave, $I(t)$ is function within $0 \sim 1$. Definition of strong vibration duration is :

$$
T_{\alpha}=t_{2}-t_{1}
$$

The relation of $t_{2}$ and $t_{1}$ is:

$$
I\left(t_{2}\right)-I\left(t_{1}\right)=\alpha \%
$$

Japanese and American researchers (Takjzawa,1980), (Jennings \& Housner,1968) compared $90 \%, 80 \%, 70 \%, 60 \%$ and $50 \%$ of energy duration for destructive effect of buildings and decided $70 \%$ of energy duration was more fitting to actual situation, the article author also analysed and computed representative seismic record in Tab.(1), in the same time considered standard deviation $\pm 5 \%$, and energy in ascent stage occupy $10 \%$ of total energy , moreover $I\left(t_{1}\right)$ is $10 \%, I\left(t_{2}\right)$ is $80 \%$.

\begin{tabular}{|c|c|c|c||c|c|c|c|}
\hline $\begin{array}{c}\text { Earthquake } \\
(\mathrm{T})\end{array}$ & $\begin{array}{c}10 \% \\
t_{1}\end{array}$ & $\begin{array}{c}80 \% \\
t_{2}\end{array}$ & $\begin{array}{c}\text { Strong } \\
\text { duration } \\
T_{\alpha}\end{array}$ & $\begin{array}{c}\text { Earthquake } \\
(\mathrm{T})\end{array}$ & $\begin{array}{c}10 \% \\
t_{1}\end{array}$ & $\begin{array}{c}80 \% \\
t_{2}\end{array}$ & $\begin{array}{c}\text { Strong } \\
\text { duration } \\
T_{\alpha}\end{array}$ \\
\hline $\begin{array}{c}\text { EI-centro } \\
(37.03 \mathrm{~s})\end{array}$ & $6.12 \mathrm{~s}$ & $10.18 \mathrm{~s}$ & $4.06 \mathrm{~s}$ & $\begin{array}{c}\text { Northridge } \\
(15.01 \mathrm{~s})\end{array}$ & $1.90 \mathrm{~s}$ & $3.80 \mathrm{~s}$ & $1.90 \mathrm{~s}$ \\
\hline $\begin{array}{c}\text { Taftew } \\
(27.11 \mathrm{~s})\end{array}$ & $1.87 \mathrm{~s}$ & $7.73 \mathrm{~s}$ & $5.86 \mathrm{~s}$ & $\begin{array}{c}\text { Chichi long } \\
(39.98 \mathrm{~s})\end{array}$ & $10.26 \mathrm{~s}$ & $15.00 \mathrm{~s}$ & $4.74 \mathrm{~s}$ \\
\hline $\begin{array}{c}\text { Kobe } \\
(46.38 \mathrm{~s})\end{array}$ & $4.00 \mathrm{~s}$ & $8.50 \mathrm{~s}$ & $4.50 \mathrm{~s}$ & $\begin{array}{c}\text { Nanjin } \\
(16.10 \mathrm{~s})\end{array}$ & $3.00 \mathrm{~s}$ & $8.90 \mathrm{~s}$ & $5.90 \mathrm{~s}$ \\
\hline $\begin{array}{c}\text { Tianjinew } \\
(19.08 \mathrm{~s})\end{array}$ & $7.26 \mathrm{~s}$ & $10.01 \mathrm{~s}$ & $2.75 \mathrm{~s}$ & $\begin{array}{c}\text { Qiananns } \\
(22.10 \mathrm{~s})\end{array}$ & $1.79 \mathrm{~s}$ & $4.74 \mathrm{~s}$ & $2.95 \mathrm{~s}$ \\
\hline $\begin{array}{c}\text { Tangshanew } \\
(49.20 \mathrm{~s})\end{array}$ & $20.9 \mathrm{~s}$ & $39.4 \mathrm{~s}$ & $18.5 \mathrm{~s}$ & $\begin{array}{c}\text { Wenchuan } \\
(500 \mathrm{~s})\end{array}$ & $11.92 \mathrm{~s}$ & $91.7 \mathrm{~s}$ & $79.78 \mathrm{~s}$ \\
\hline
\end{tabular}

Table 1. Statistics and analysis of strong vibration duration in earthquake record

Tri-stage curve and exponent curve have been accepted widely now by engineering because of simple, visualized and physical significance (Ohsaki,1978;Kaul,1978;Amin \& Ang, 1968 ), tri-stage curve could be shown as: 


$$
g(t)=\left\{\begin{array}{lc}
\left(t / t_{1}\right)^{2} & t \leq t_{1} \\
1 & t_{1}<t \leq t_{2} \\
\exp \left[-c\left(t-t_{2}\right)\right] & t>t_{2}
\end{array}\right.
$$

Where $t_{1}, t_{2}$ and $c$ are model parameters, $t_{1}$ and $t_{2}$ are begin moment and end moment, $c$ present weakening velocity in descent stage, $T_{s}$ is vibration duration in strong vibration duration for 70\% energy of total seismic energy, in which $t_{1}=0.5 T_{s}, t_{2}=1.2 T_{s}, c=2.5 / T_{s}$.

Exponent curve is shown as $g(t)=\beta t e^{-\alpha t}$, in which $\alpha$ and $\beta$ is model parameter, $\alpha=0.01$, $\beta=0.028$.

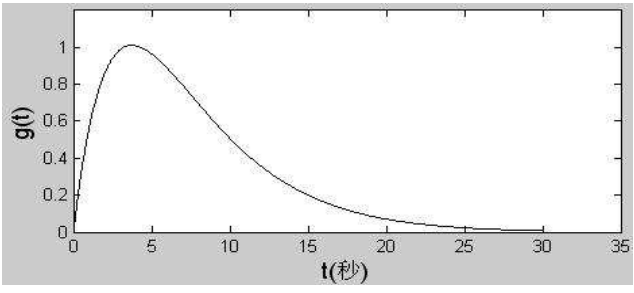

a

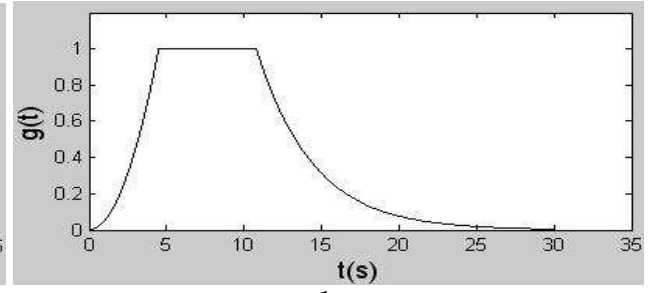

b

Fig. 2. Envelop curve (a: exponent form, b: tri-stage form)

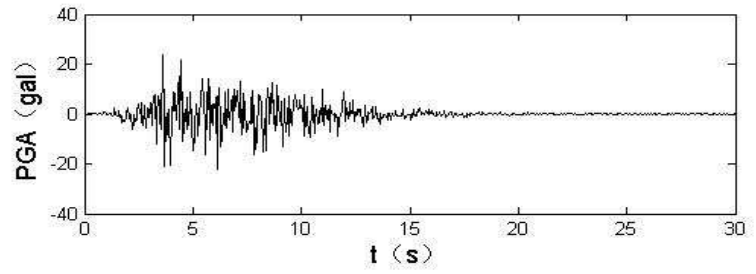

Fig. 3. Initial stationary artificial stochastic acceleration time history

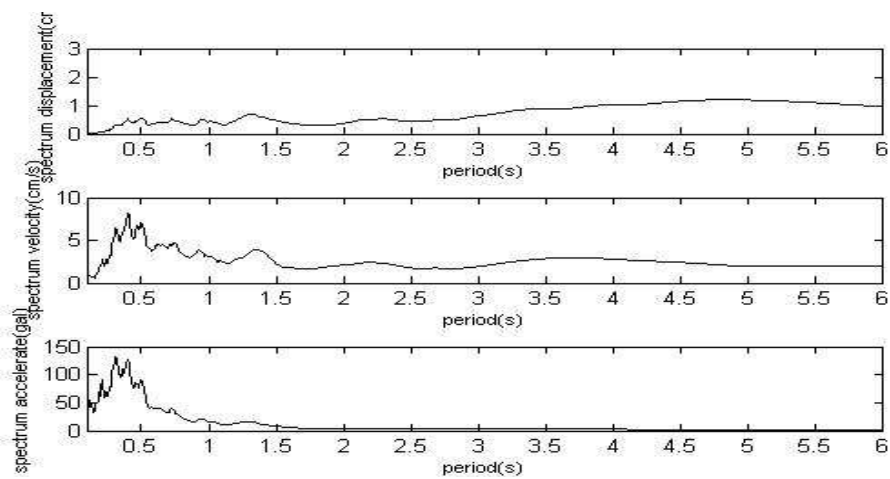

Fig. 4. Initial artificial stochastic response spectrum(from top to bottom: spectrum displacement, spectrum velocity, spectrum acceleration) 


\subsection{Artificial seismic record update}

If initial artificial seismic response spectrum from record $a_{0}(t)$ isn't meet degree of fitting with specify earthquake response spectrum or code response spectrum, there has need to update for more precision. Generally two ways now have been used for updating. The article used the second method.

First method :

$$
A_{i}^{\prime}(t)=\frac{S_{V}}{S_{V}{ }^{\prime}} A_{i}(t)
$$

Where $A_{i}^{\prime}(t)$ is updated Fourier spectrum, $A_{i}(t)$ is Fourier spectrum of initial artificial record, $S_{V}$ is target response spectrum velocity, $S_{V}{ }^{\prime}$ is spectrum velocity of initial record.

Second method :

$$
S_{g}{ }^{\prime}(\omega)=S_{g}(\omega)\left[\frac{\operatorname{TRSA}(\omega)}{\operatorname{SRSA}(\omega)}\right]^{2}
$$

Where $S_{g}{ }^{\prime}(\omega)$ is updated power spectrum density, $S_{g}(\omega)$ is initial power spectrum density, $\operatorname{TRSA}(\omega)$ is intend to compared target response spectrum, $S R S A(\omega)$ is computed stationary artificial seismic response spectrum, next step compute new steady artificial wave and multiply seismic envelop curve for updating new stationary artificial seismic wave, the updating could be repeated several times until degree of fitting is satisfy with accuracy. It is aware of that we need to control frequency in updating process, at first spectrum acceleration value of control points need be computed out, secondly comparing with control points of frequency, adjust ratio between two points need linear interpolation method to compute. As shown in Tab. 2.

\begin{tabular}{|c|c|c|}
\hline \hline The number of control points & \multicolumn{2}{|c|}{ Frequency Range $(\mathrm{Hz})$} \\
\hline \hline 5 & 0.10 & 0.18 \\
\hline 29 & 0.20 & 3.00 \\
\hline 4 & 3.15 & 3.60 \\
\hline 7 & 3.80 & 5.00 \\
\hline 11 & 5.25 & 8.00 \\
\hline 14 & 8.50 & 15.00 \\
\hline 4 & 16.00 & 30.00 \\
\hline
\end{tabular}

Table 2. Frequency adjust control points for artificial wave

Fig. 5-6 are updated samples for intensity 9 from (Chinese Seismic Code, 2001). The program iterative computed 5 8 times and result meet degree of fitting with Chinese code response spectrum, now artificial wave after updated was fitting to code response spectrum, 120 seismic record fitting to major earthquake and code response spectrum were created in this way and become applied load for next computation. 

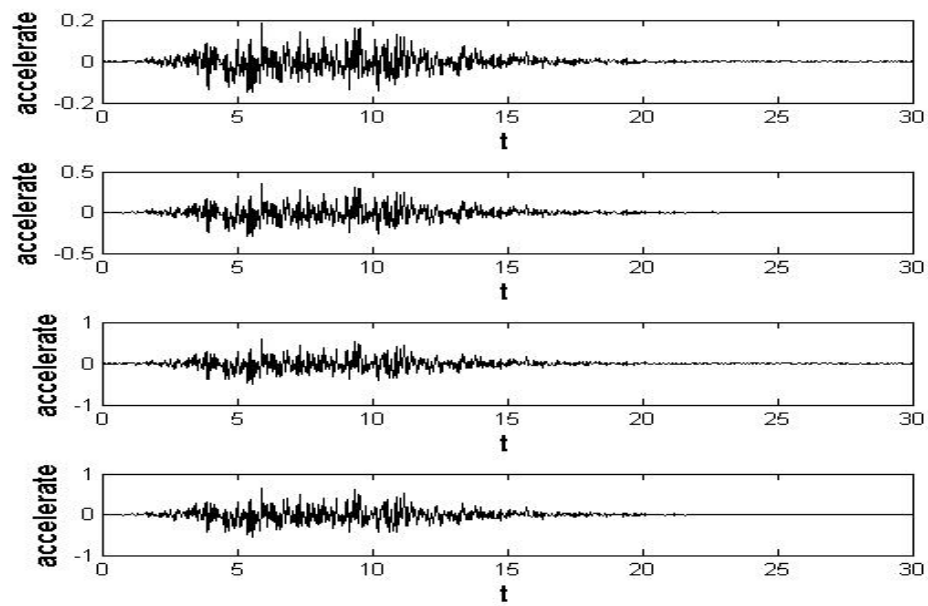

Fig. 5. Updating process of artificial seismic acceleration

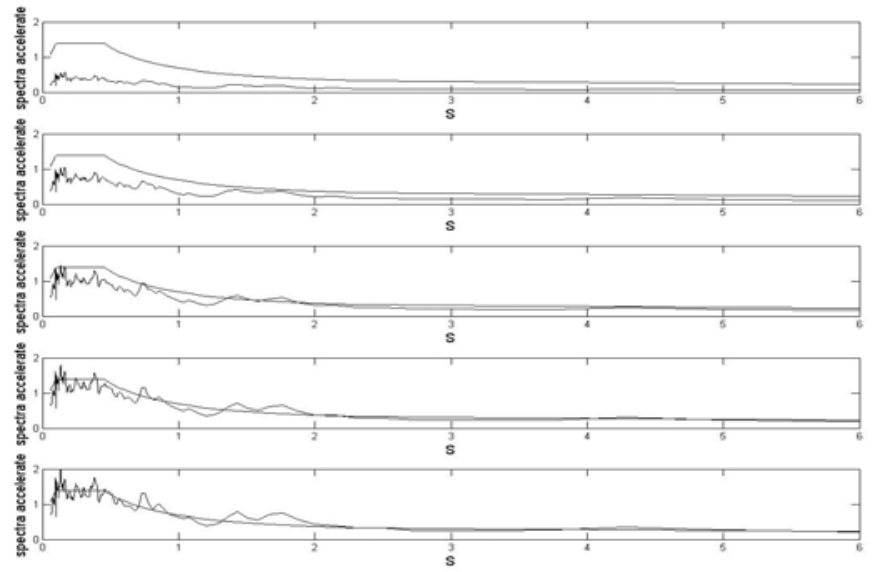

Fig. 6. Updating process of artificial response spectrum

\section{Proposed damage index of frame buildings}

At the moment seismic theory of China is more emphasis in prevent buildings collapse instead of prevent structural damage, first aim of buildings design is prevent collapse in major earthquake but obvious plastic deformation and damage is evitable, and key point is how to assure structural damage within acceptable degree based moment code, especially many lifeline constructions for example: nuclear energy station, bridge, tunnel, gymnasium and important factory buildings, so design based performance now have been approved widely, and content of structural vulnerability index is significant part of design based performance. Damage index in early research mainly emphasis in member ductility, ductility ratio could be define as curvature $\mu_{\phi}$, rotation $\mu_{\theta}$ and deformation $\mu_{\delta}$, 


$$
\mu_{\phi}=\phi_{m} / \phi_{y} \quad \mu_{\theta}=\theta_{m} / \theta_{y} \quad \mu_{\delta}=\delta_{m} / \delta_{y}
$$

Where $\phi_{m}, \theta_{m}$ and $\delta_{m}$ are respectively maximum curvature, maximum rotation and maximum deformation of member end, $\phi_{y}, \theta_{y}$ and $\delta_{y}$ are respectively yielding curvature, yielding rotation and yielding deformation.

(Banon,1982) also proposed a correctional ductility parameter that considering structural rigid and strength degeneration in same time,

$$
F D R=K_{o} / K_{m}
$$

Where $K_{o}$ is initial tangent stiffness, $K_{m}$ is equivalent tangent stiffness after maximum reaction. But in fact whether ductility ratio or correctional ductility ratio all could not give accurate judgment for structural damage and invalid.

Another damage index is relative storey displacement or relative storey rotation, in which relative storey rotation is widely accepted as estimate damage index at present in fragility research, in many research articles the index have taken as fragility standard in reinforced concrete buildings, and that relate to compatibility and effective in judging structural damage, that is to say that the index has characteristic in revealing both whole damage and local damage, and more better express structural whole damage compare with building bearing capacity, HAZUS99 series damage evaluation manual of US also adopted relative storey rotation as seismic vulnerability index.

Above both index could not reflect material accumulative damage effect, so other scholars lately proposed some index with accumulative damage effect, in which Park-Ang damage index is widely influence, the index is consist of two parts as shown in Eq. (12), and one is transformation effect and second is absorbing energy effect.

$$
D=\frac{\delta_{m}}{\delta_{u}}+\beta_{e} \frac{\int d E}{F_{y} \delta_{u}}
$$

Where $D$ damage parameter, $\delta_{m}$ is maximum seismic transformation, $\int d E$ is accumulative absorbing hysteresis energy, $\delta_{u}$ is ultimate deformation under monotonic loading, $F_{y}$ is yielding strength with longitudinal steel bars, $\beta_{e}$ is constant damage parameter under considering hysteresis loading, which is connect with ratio of shear span to effective depth of section, axial-load ratio, ratio of longitudinal reinforcement and stirrup ratio.

Damage parameter $D$ is function with structural maximum deformation $\delta_{m}$ and whole hysteresis energy $\int d E$, which is connect to loading time history, while the quantities $\beta_{e}$, $\delta_{u}$ and $F_{y}$ are independent of the loading history and are determined from experimental tests (Moustafa,2011), $D \geq 1$ means that buildings damage completely and could not bear loading.

$$
\beta_{e}=\left[0.37 n_{0}+0.36\left(k_{p}-0.2\right)^{2}\right] 0.9^{100 \rho_{c}}
$$


Where $n_{0}=N /\left(b d f_{c}^{\prime}\right)$ is standard axial loading, which is 0.05 when it less than $0.05, \rho_{c}$ is stirrup ratio, which is stirrup volume compare to core concrete volume, and is 0.004 when less than $0.004, k_{p}=\rho_{p} f_{y p} /\left(0.85 f_{c}^{\prime}\right)$ is standard reinforcement ratio.

$$
\delta_{u}=0.0052\left(\frac{l_{s}}{d}\right)^{0.93}\left(0.85 k_{p}\right)^{-0.27}\left(\frac{100 \rho_{c}}{n_{0}}\right)^{0.48}\left(\frac{f_{c}^{\prime}}{0.6895}\right)^{-0.15} l_{c}
$$

Where $l_{s}$ is span length with shearing, $l_{c}$ is respective member length or height, $f_{c}^{\prime}$ is uniaxial concrete compression strength, unit is $\mathrm{kN} / \mathrm{cm}^{2}, d$ is effective height, units is $\mathrm{cm}$.

In 1985, Park suggested that set $D=0.4$ as limit line between repairable and irreparable, in 1987, he proposed more detailed qualitative classified chart of concrete buildings' damage, as shown in Tab. 3.

\begin{tabular}{|c|c|}
\hline$D<0.1$ & Undamaged or localized trivial crack \\
\hline $0.1 \leq D<0.25$ & Light damage - trivial crack throughout \\
\hline $0.25 \leq D<0.4$ & Moderate damage-severe crack and localized buckling \\
\hline $0.4 \leq D<1$ & Severe damage-concrete crashing and reinforcing bars exposure \\
\hline$D \geq 1$ & collapse \\
\hline
\end{tabular}

Table 3. Qualitative damage description for concrete buildings (Park \& Ang, 1985)

Strength and stiffness degeneration is main characteristic of material and structure damage, because of high variability of stiffness degeneration in cylinder-load lead to difficult in actual application, in 2005 Colombo-Negro proposed modified Park-Ang damage parameter model corresponding to strength degeneration, and which is defined:

$$
\begin{aligned}
D & =1-\frac{M_{a c}}{M_{y o}} \\
& =1-\left(\left(1-\frac{\mu_{\max }}{\mu_{u}}\right)^{1 / \beta_{1}} \cdot 0.5\left(1-\tanh \left(\beta_{2} \frac{\int d E}{E_{u}^{*}}-\pi\right)\right) \cdot \exp \left(-\beta_{3} \frac{\int d E}{E_{u}^{*}}\right)\right)
\end{aligned}
$$

Where $M_{a c}$ is yield force or moment actual degradation value, $M_{y o}$ is force or moment of theoretical yielding point on skeleton envelop curve, $\mu_{\max }$ is attainable deformation ductility, $\mu_{u}$ is ultimate ductility, $E_{u}^{*}$ is ultimate cylinder energy, $\beta_{1}$ is coefficient of harden slope or soften slope in stress-strain curve, $\beta_{2}$ is consuming energy point in structure damage model when resistance force sloping, $\beta_{3}$ is strength dropping ratio in fragility damage model, as shown in Tab. 4. 


\begin{tabular}{|c|c|c|c|c|c|}
\hline coefficient & $(\mathrm{a})$ & $(\mathrm{b})$ & $(\mathrm{c})$ & $(\mathrm{d})$ & $(\mathrm{e})$ \\
\hline $\begin{array}{c}\text { Ductility-based strength decay } \\
\text { parameter } \beta_{1}\end{array}$ & 0.10 & 0.10 & 0.10 & 0.15 & 0.15 \\
\hline $\begin{array}{c}\text { Energy-based ductility strength decay } \\
\text { parameter } \beta_{2}\end{array}$ & 2.40 & 3.20 & 7.00 & 0.10 & 0.10 \\
\hline $\begin{array}{c}\text { Energy-based brittle strength decay } \\
\text { parameter } \beta_{3}\end{array}$ & 0.10 & 0.10 & 0.10 & 9.00 & 2.20 \\
\hline
\end{tabular}

(a) Damage behavior of well confined reinforced concrete columns. (b) Damage behavior of concrete-filled steel rectangular columns. (c) Damage behavior of welded steel joints. (d) Damage behavior of poorly confined reinforced concrete columns. (e) Damage behavior of shear-deficient reinforced concrete walls.

Table 4. Damage model coefficient suggested value (Colombo \& Negro,2005)

Where assuming system is double linear hysteresis model, post-yield stiffness is equal $3 \%$ of elastic yielding stiffness, so when ductility $=\mu$, hysteresis consumed energy is shown as Eq.(16).

$$
\int d E=\frac{1}{2} \mu_{y} f_{e}-\mu_{y} f_{y}\left(\mu-\frac{1}{2}\right)
$$

Where $\mu_{y}$ is yielding deformation, $f_{e}$ is yielding strength of equivalent linear system, $\frac{1}{2} \mu_{y} f$ is energy of equivalent linear system, $\mu_{y} f_{y}\left(\mu-\frac{1}{2}\right)$ is energy of plastic system, ultimate hysteresis energy is

$$
E^{*}=\mu_{y} f_{e}\left(\frac{1}{2}-\mu_{u} \bar{f}_{y u}+\frac{1}{2} \bar{f}_{y u}\right)
$$

Where $\bar{f}_{y u}$ ultimate standard yielding strength, and assumed as 0.8 , in according with above equations that could compute Colombo-Negro adjusted damage coefficient of specific structure

\begin{tabular}{|c|c|}
\hline Damage Scale & Value Range \\
\hline Light damage & $0.01-0.10$ \\
\hline Moderate damage & $0.10-0.40$ \\
\hline Severe damage & $0.40-0.70$ \\
\hline collapse & $>0.70$ \\
\hline
\end{tabular}

Table 5. Colombo-Negro suggested revised damage index for different limit states

One of primary object for calculate damage parameters is decided level of limit-value of different damage coefficient, and provide vulnerability scale for later seismic vulnerability analysis.

\section{Finite element and frame modeling}

In order to assess the adequacy of results obtained from Finite Element (FE) analyses have been carried out. The reinforced concrete models have been conducted with SeismoStruct 
V5.0, a fibre-element based professional 3D program for seismic analysis of framed structures, which can be freely downloaded from the Internet. The program is capable of predicting the large displacement behavior and the collapse load of framed structures under static or dynamic loading, duly accounting for geometric nonlinearities and material inelasticity. Section with fibre-element of column or beam is shown as Fig.7, and 200 fibre elements fulfill calculated requirement.

Distributed fibre inelasticity elements are becoming widely employed in earthquake engineering applications, Whilst their advantages in relation to nonlinear constant-confined concrete model theory proposed by (Madas,1992), (Martinez-Rueda J.E. \& Elnashai A.S.,1997) in 1990s, which uniaxial stain-stress relationship shown as Fig.8a, skeleton envelop curve could reflect confinement effect and hysteresis-stiffness degenerated characteristic. Steel stress-strain relationship proposed by (Menegotto and Pinto,1973), coupled with the isotropic hardening rules proposed by (Filippou,1983). The current implementation follows that carried out by (Monti \& Nuti, 1992). Its employment should be confined to the modelling of reinforced concrete structures, particularly those subjected to complex loading histories, where significant load reversals might occur. As discussed by (Prota et al.,2009), with the correct calibration, this model, initially developed with ribbed reinforcement bars in mind, can also be employed for the modelling of smooth rebars, often found in existing structures, as shown in Fig.8b.

In the article frame models proposed by (Ghobarah et al.,1999), who had been calculated on the based above fibre element, results coincide with results from general finite element program Drain-2D, in the same time, its accuracy in predicting the seismic response of reinforced concrete structures has been demonstrated through comparisons with experimental results derived from pseudo dynamic tests carried out on large-scale models (Casarotti et al.,2005).

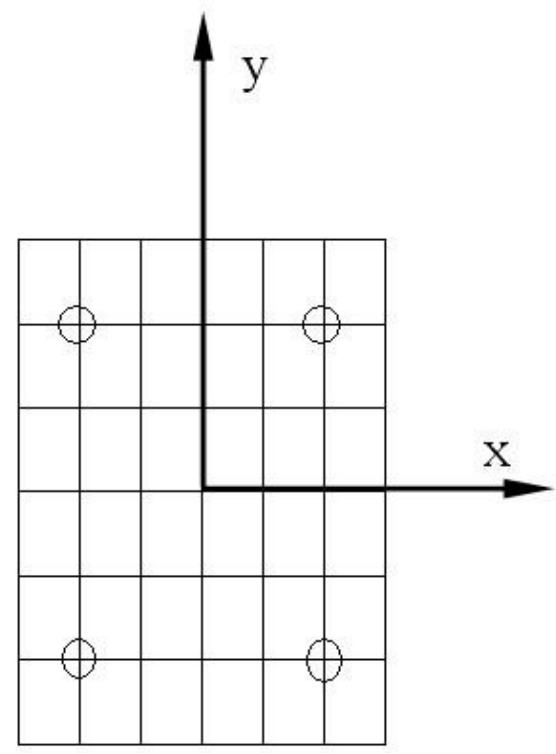

Fig. 7. Fibre in Section 


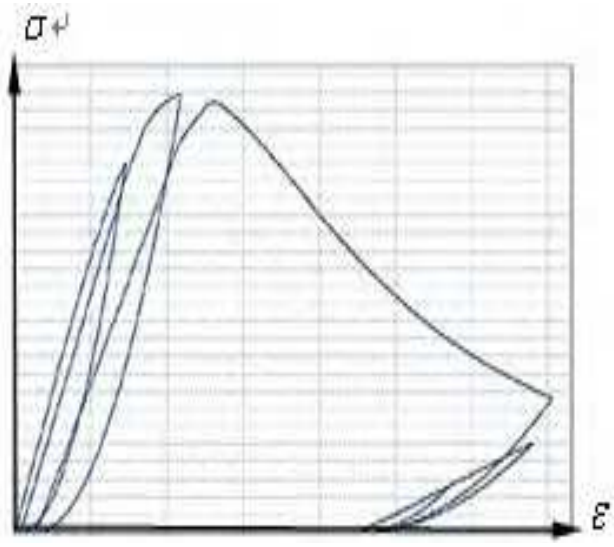

a

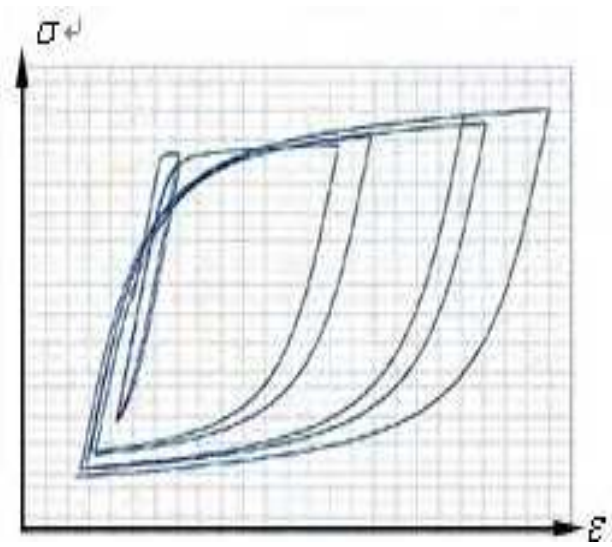

$\mathrm{b}$

Fig. 8. Material stress-strain model (a: concrete b: steel bar)

\section{Seismic vulnerability analysis of $\mathrm{RC}$ shear wall frame buildings}

At present, there are still many RC buildings in Western China regions. Most of them are small high-rise (12 16 storey) RC frames in recent years. The sample buildings were designed according to the prescriptions for loading, material, member dimensioning and detailing of the seismic design and gravity load design codes in place in China in 2002.

The full design of the sample RC frame in Western China is presented in Fig.9

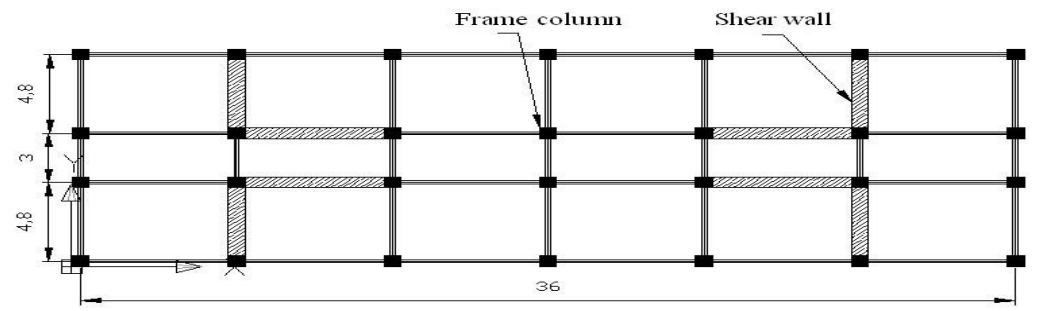

Fig. 9. Plan of typical frame-shear wall structure of 12-story

The structure consists of seven frames with bay width of $4.8 \mathrm{~m}, 3 \mathrm{~m}, 4.8 \mathrm{~m}$ respectively and frame spacing of $6 \mathrm{~m}$. It is symmetrical in plan and elevation, and RC beam section is $0.60 \mathrm{~m} \times 0.30 \mathrm{~m}$, at the same time RC column is $0.60 \mathrm{~m} \times 0.60 \mathrm{~m}$, which connected beams around the building at the corner and intersect with inner columns of building. Thickness of RC shear-wall is $0.3 \mathrm{~m}$ and floors consist of cast-in place reinforced concrete slabs is $120 \mathrm{~mm}$ thick.

Diameter longitudinal reinforcements of columns and beams' section are revealed in Fig.10, 8mm diameter stirrups must be spaced $100 \mathrm{~mm}$ apart at the extremes and $200 \mathrm{~mm}$ at the centre of the elements. The stress method used for the design is according to China seismic code.

The gravity load scenario consists of dead load and live load. When calculating the dead load, the weight of the structural members and the infill walls was included. The live load 
used was $2.5 \mathrm{kN} / \mathrm{m}^{2}$, which is typical for school building. Other types of loading, such as wind and snow, were not considered.
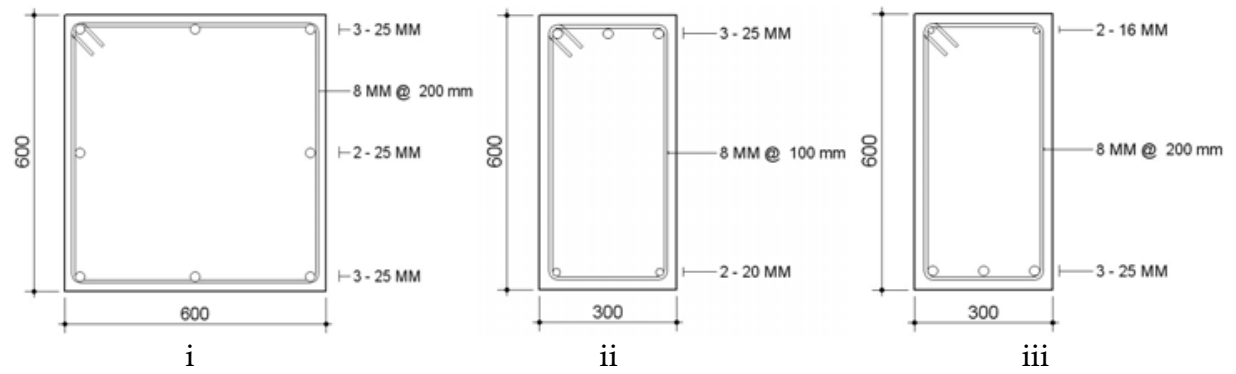

Fig. 10. Reinforced bars of section (i: column ii: side-beam iii:mid-beam )

Because of complicated climate in China all of year, the concrete strength must at least C30 according to China seismic code, reinforced bar (HPB235 HRB335) strength is 235 and 335 Mpa respectively, concrete strength is $30 \mathrm{Mpa}$, the stress-stain relationship are illustrated in Fig.8.

Ground motion characteristics have a significant effect on the vulnerability curves and special attention is required during the record selection phase in Fig.11.
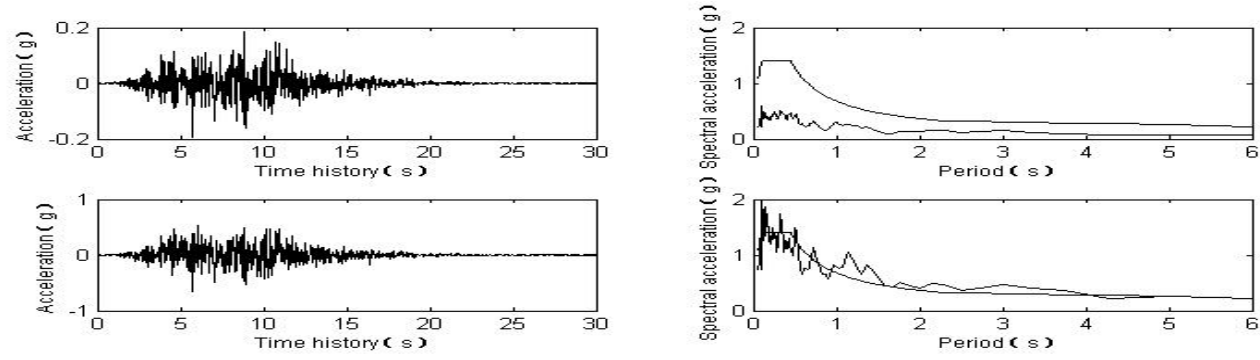

Fig. 11. Stochastic record compatible with the target spectrum of China code

\subsection{Determination of limit states}

The aim of this analysis is to evaluate the building's potential seismic performance. Four limit state conditions have been taken into account: light damage, moderate damage, extensive damage and complete damage. So if a building deformation beyond the extensive damage limit state it might not be economically advantageous to repair the building because many of the school buildings of Sichuan region were being set up without carefully thought of structural seismic codes of China.

\begin{tabular}{|c|c|c|c|c|c|}
\hline $\begin{array}{c}\text { Limit } \\
\text { state }\end{array}$ & $\begin{array}{c}\text { Inter-storey } \\
\text { drift }(\mathrm{mm})\end{array}$ & $\begin{array}{c}\text { Inter-storey } \\
\text { drift ratio(\%) }\end{array}$ & $\begin{array}{c}\text { Limit } \\
\text { state }\end{array}$ & $\begin{array}{c}\text { Inter-storey } \\
\text { drift }(\mathrm{mm})\end{array}$ & $\begin{array}{c}\text { Inter-storey } \\
\text { drift ratio(\%) }\end{array}$ \\
\hline $\begin{array}{c}\text { Light } \\
\text { Moderate }\end{array}$ & 6.6 & 0.20 & Extensive & 33.0 & 1.00 \\
Complete & 82.5 & 2.00 \\
\hline
\end{tabular}

Table 6. Limit states and corresponding inter-storey drifts ratios(ISD\%) 


\subsection{Vulnerability curve}

Dynamic time-history analysis is used to evaluate the seismic response and to derive the vulnerability curve. This approach is the most tedious but it is also the more accurate way to assess the vulnerability of RC buildings in China. The selected frame was subject to each group of the stochastic artificial records.

The stochastic damage scatter diagram and damage versus hazard relationship of the typical $\mathrm{RC}$ frame is illustrated in Fig.12. The damage axis (y-axis) described as the hazard axis ( $x-$ axis) is described as spectral acceleration pga. Each vertical line of scattered data corresponds to an intensity level. The horizontal lines in the figure represent the limit states used in this study and described in terms of ISD\%.

A statistical distribution is fitted to the data for each intensity level on each vertical line. The normal parameters, the mean $M_{d s}$ and standard deviation $\beta_{d s}$ of the damage state are calculated for each of these $S_{k}$ intensity levels. At each intensity level, the probability of exceeding each limit state is calculated. LS1, LS2, LS3 and LS4 represent the limit states for light, moderate, extensive and complete damage, respectively, as mentioned above. The mean and standard deviation values of the response data are also given in the Fig.13.

The probability of exceedance of a certain limit state is obtained by calculating the area of the standard normal distribution over the horizontal line of that limit state.
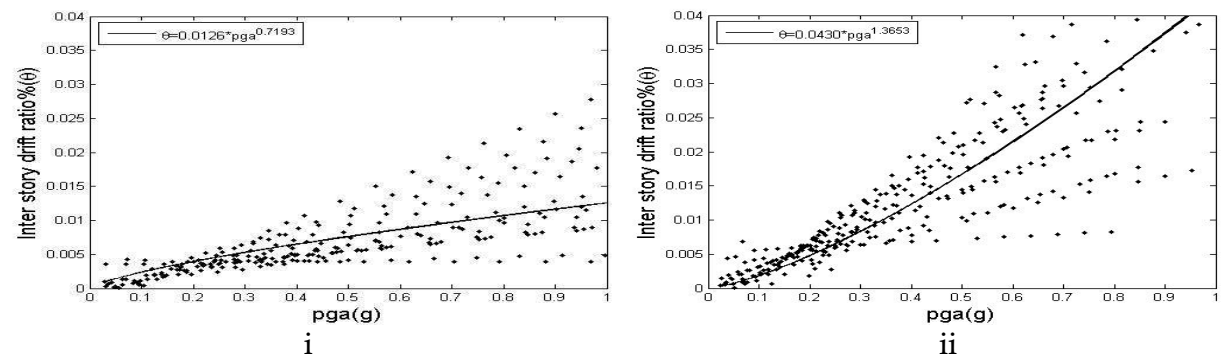

Fig. 12. Damage scatter dots relationship with PGA-ISD $\%_{\max }$ (i:X axis; ii:Y axis)
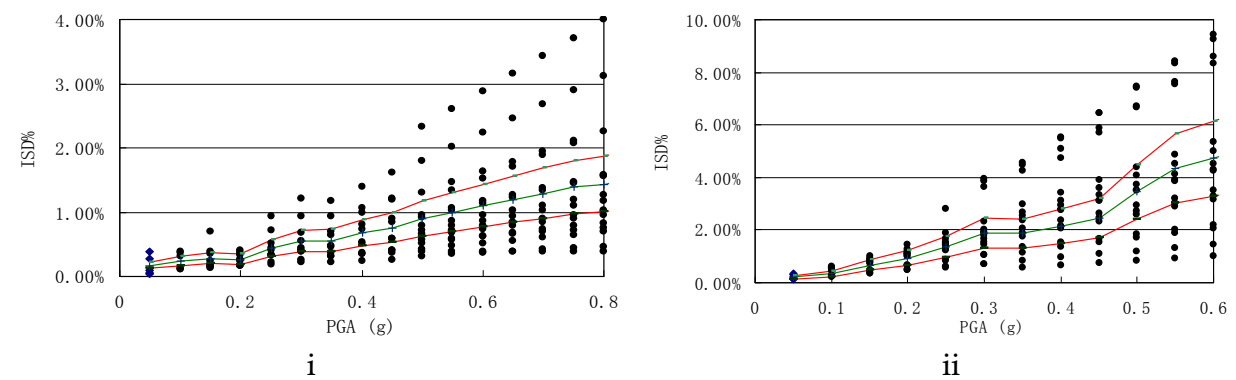

Fig. 13. Damage column dots plot with PGA-ISD\% ${ }_{\max }$ (i:X axis; ii:Y axis)

After calculating the probability of exceedance of the limit state for each intensity level, the vulnerability curve can be constructed by plotting the calculated data versus spectral acceleration. In this study, a standard deviation fit is assumed as 0.3. 
Figure.14 represents the vulnerability curves of typical frame-shear wall buildings in China with different spectral characteristic parameter. The curves become flatter as the nature of the statistical distribution of the response data. Vertical curves would represent deterministic response.
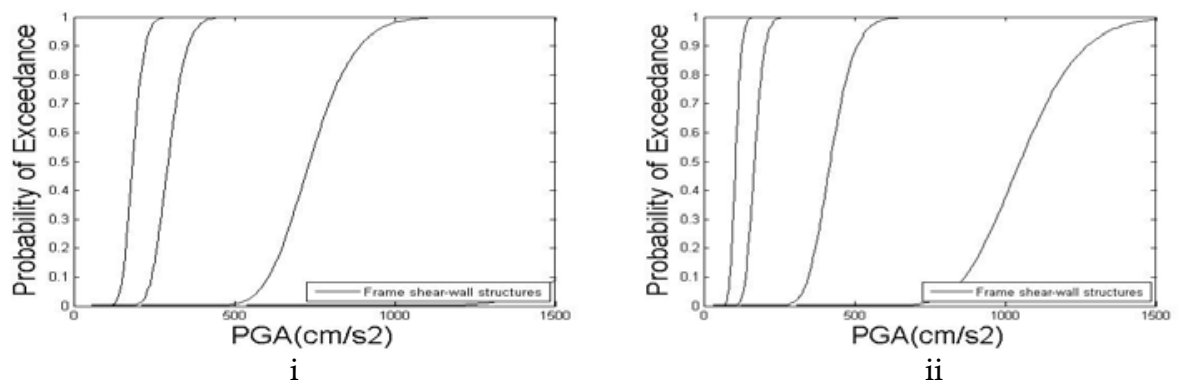

Fig. 14. Vulnerability curves with respected PGA (i : X axis; ii : Y axis)

\section{Seismic vulnerability analysis of structures with mid-story seismic isolation and reduction (MIRS)}

At present, there are many new built RC buildings in China large cities because of rapid developing economy. The buildings are designed according to the prescriptions for loading, material, member dimensioning and detailing of the seismic design and gravity load design codes in place in China in 2002.

The full design of the typical 12 stories MIRS in China is presented in Fig.15.

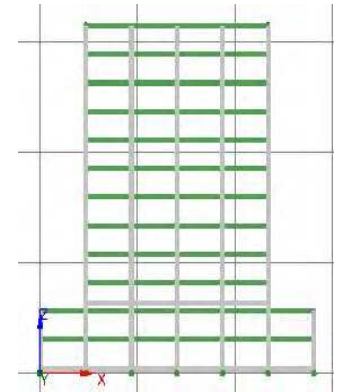

i. front façade

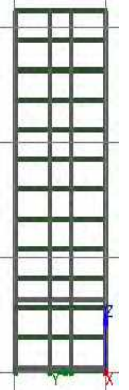

ii. left

facade view

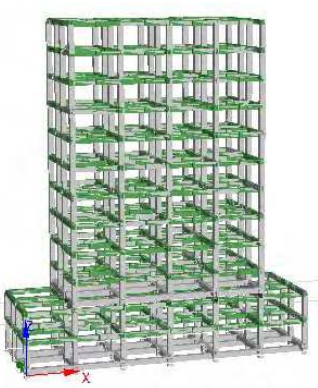

iii. $3 \mathrm{D}$ globe view

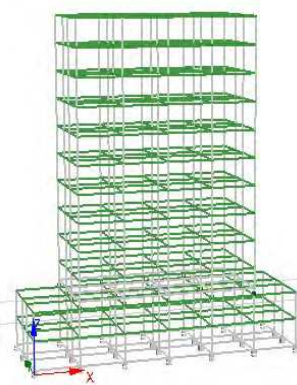

iv. 3D finite model with inelastic bars

Fig. 15. The full design of the typical MIRS in China

The structure consists of seven frames with bay width of $4.8 \mathrm{~m}, 3 \mathrm{~m}, 4.8 \mathrm{~m}$ respectively and frame spacing of $6 \mathrm{~m}$. It is symmetrical in plan and elevation, and RC beam $\left(0.6 \times 0.35 \mathrm{~m}^{2}\right)$ around the exterior perimeter and along the top of interior longitudinal and transverse columns in all the floors of the building including ground base level according China code. At the same time RC column $\left(0.6 \times 0.6 \mathrm{~m}^{2}\right)$ which connected beams around the building at the corner and intersect with inner columns of building. Story height is $3.3 \mathrm{~m}$, floors consist of 
cast-in place reinforced concrete slabs is $120 \mathrm{~mm}$ thick. Reinforcement of section of MIRS is shown in Fig.16.
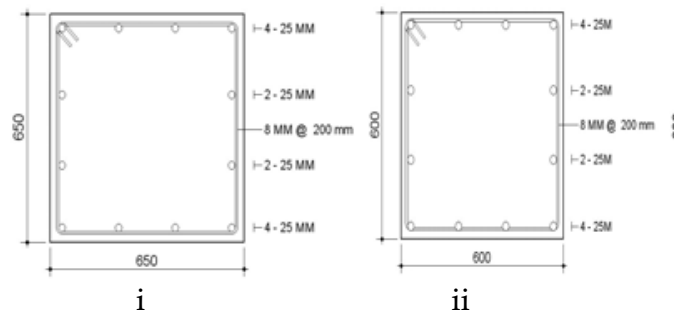

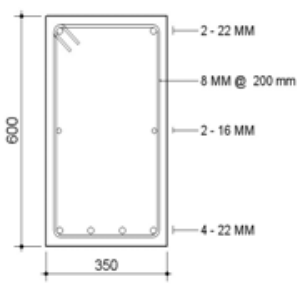

iii

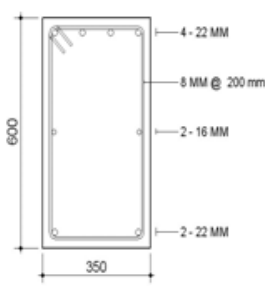

IV

Fig. 16. Reinforcement of section of MIRS (i: column section of subway platform ii:column section on isolation layer iii: mid-beam section iv: side-beam section)

Columns have twelve $20 \mathrm{~mm}$ diameter longitudinal reinforcements, $8 \mathrm{~mm}$ diameter stirrups must be spaced $100 \mathrm{~mm}$ apart at the extremes and $200 \mathrm{~mm}$ at the centre of the elements, beams have four tension bars and two compressive bars. The stress method used for the design is according to China seismic code.

The gravity load scenario consists of dead load and live load. When calculating the dead load, the weight of the structural members and the infill walls was included. The live load used was $2.5 \mathrm{kN} / \mathrm{m}^{2}$, which is typical for city tall building. Other types of loading, such as wind and snow were not considered.

\subsection{Material and member property}

Because of moist climate in Sichuan district all of year, the concrete strength must at least C30 according to China seismic code, reinforced bar strength is 235 and $335 \mathrm{Mpa}$ respectively, concrete strength is $30 \mathrm{Mpa}$.

Design of laminated rubber bearing is chosen LRB-G4-850-180 based China isolation design code(CECS126,2001), the key parameters of bearing are: equivalent damping ratio is 0.27 , secant stiffness ratio is 0.128 , initial stiffness $k_{0}$ is $18100 \mathrm{KN} / \mathrm{m}$, yielding force $F_{y}$ is $203 \mathrm{KN}$ and post yielding ratio is 0.1 , laminated rubber bearing stress-strain relationship is shown in Fig.17.

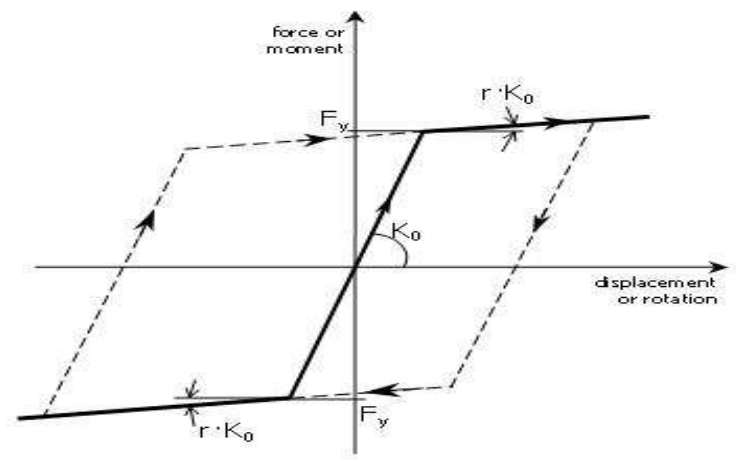

Fig. 17. Rubber bearing stress-strain model 


\subsection{Analytical model}

In order to evaluating seismic vulnerability of MIRS accurately, the building is modeled as a 3-D pole frame with lumped masses the study when assessing seismic response. Inelastic frame elements means 3D beam-column elements capable of modeling members of space frames with geometric and material nonlinearities with 5\% global damp coefficient.

Ground motion characteristics have a significant effect on the fragility curves and special attention is required during the record selection phase. Considering this fact, 30 corrected stochastic artificial ground motions have been used in this study from different PGA covering a wide range of characteristics with a magnitude range between 5.1 and 7.8 . The motions are generally recorded on soft to medium sites according to Sichuan region's circumstance where basis prominent period range from $0.35 \mathrm{~s}$ to $0.45 \mathrm{~s}$ according China seismic code and crossed over the foundation in random orientation within $\mathrm{x}$-direction or $\mathrm{y}$ direction or both direction, as shown in Fig.11.

\subsection{Damage level definition}

The aim of this analysis is to evaluate the building's potential seismic performance, establishing a relation between the intensity of the seismic action and different damage states up to collapse. so damage level is defined according to the cracking, yielding or collapse of a set of elements or connections in the structure, as presented following Table.7 .

In view of being prone to brittle shear injury of inner brick masonry wall under strong motion, four limit state conditions have been taken into account: light damage, moderate damage, extensive damage and complete damage. So if a building deforms beyond the extensive damage limit state it might not be economically advantageous to repair the building because many of the school buildings of Sichuan region were being set up without carefully thought of structural seismic codes of China.

\begin{tabular}{|c|c|c|}
\hline Limit state & Inter-story drift $(\mathrm{mm})$ & ISD ratio(\%) \\
\hline Light damage & 6.6 & 0.20 \\
Moderate damage & 16.5 & 0.50 \\
Extensive damage & 33.0 & 1.00 \\
Collapse & 99.0 & 3.00 \\
\hline
\end{tabular}

Table 7. Limit States and corresponding inter-story drifts ratios(ISD\%)

\subsection{Fragility curve}

Dynamic time-history analysis is used to evaluate the seismic response and to derive the fragility curve. This approach is the most tedious but it is also the more accurate way to assess the vulnerability of MIRS in China. The selected frame was subject to each group of the stochastic artificial records. The stochastic damage scatter diagram of the typical MIRS is illustrated in Fig.18.

A statistical distribution is fitted to the data for each intensity level on each vertical line. The normal parameters, the mean $M_{d s}$ and standard deviation $\beta_{d s}$ of the damage state are calculated for each of these Sa intensity levels. At each intensity level, the probability of exceeding each limit state is calculated. LS1, LS2, LS3 and LS4 represent the limit states for light, moderate, extensive and complete damage, respectively, as mentioned above. The mean and standard deviation values of the response data are also given lately. 

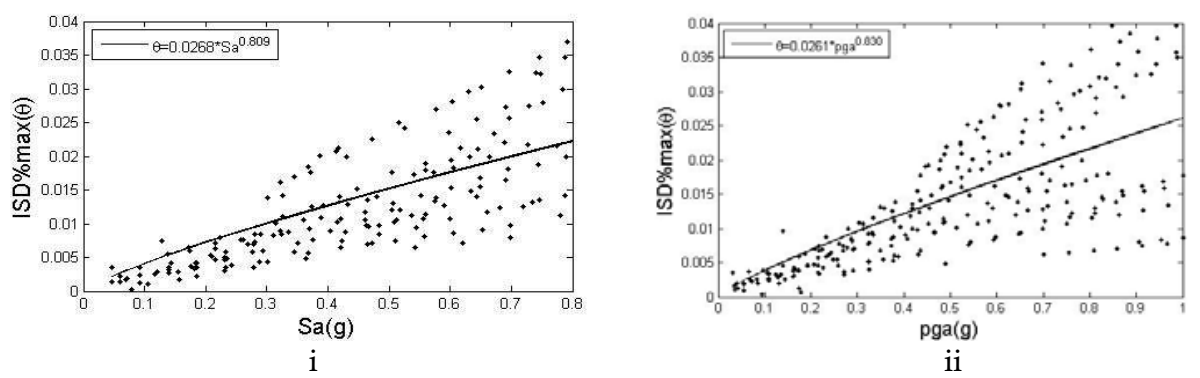

Fig. 18. Stochastic damage scatter diagram for MIRS(i : Sa; ii: PGA)

The probability of exceedance of a certain limit state is obtained by calculating the area of the standard normal distribution over the horizontal line of that limit state.

After calculating the probability of exceedance of the limit state for each intensity level, the vulnerability curve can be constructed by plotting the calculated data versus spectral acceleration. In this study, a standard deviation fit is assumed as 0.3.

Fig.19 represents the fragility curves of typical MIRS in China with different spectral characteristic parameter. The curves become flatter as the nature of the statistical distribution of the response data. Vertical curves would represent deterministic response.
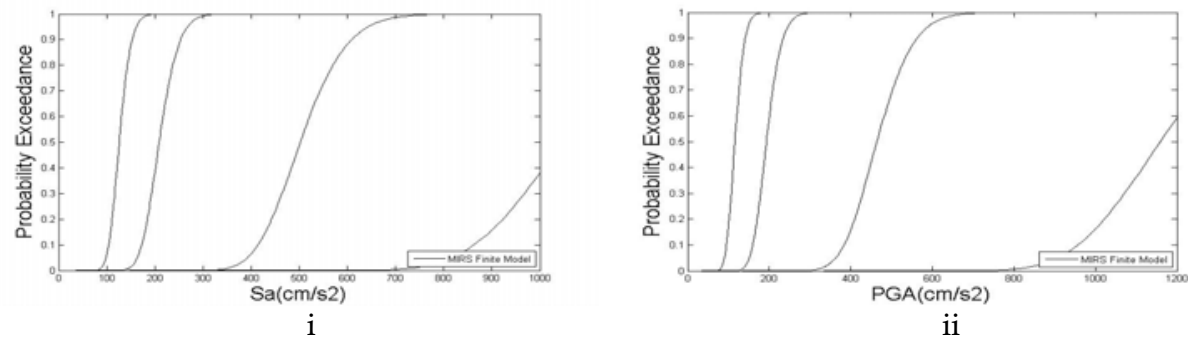

Fig. 19. Vulnerability curve for typical MIRS of China (i : Spectral accelerate; ii: PGA)

\section{Seismic vulnerability analysis of RC industrial buildings}

At present, there are many new built and old RC industrial buildings in Western China because of rapid developing economy. The buildings are designed according to the prescriptions for loading, material, member dimensioning and detailing of the seismic design and gravity load design codes of China.

The full design of the typical 12 stories MIRS in China is presented in Fig.20.

The structure consists of two frames with general configuration of bent widths and bay widths of $6 \mathrm{~m}$ and $24 \mathrm{~m}$ respectively, so the whole building have 66 meters long with 12 columns and $24 \mathrm{~m}$ width, It is symmetrical in plan and elevation, and rectangular reinforced concrete ring beam $\left(\begin{array}{ll}0.30 & 0.40 \mathrm{~m} 2\end{array}\right)$ on the bracket of two side longitudinal columns of the building. At the same time RC column $\left(\begin{array}{ll}0.40 & 0.60 \mathrm{~m} 2\end{array}\right)$ which connected ring beam as confined frame element array along the exterior side of the building at the intersect with inner confined brick wall between columns. The roof of building which 
height selected is $9.6 \mathrm{~m}$ consist in steel fibres truss, the truss depth is changed from $2.4 \mathrm{~m}$ in centre to $1.5 \mathrm{~m}$ of two sides, there are four kind of circular hollow rod being defined to using with diameter from $0.03 \mathrm{~m}$ to $0.05 \mathrm{~m}$, and thickness of bar' section is also verify from 2 to $3 \mathrm{~mm}$.

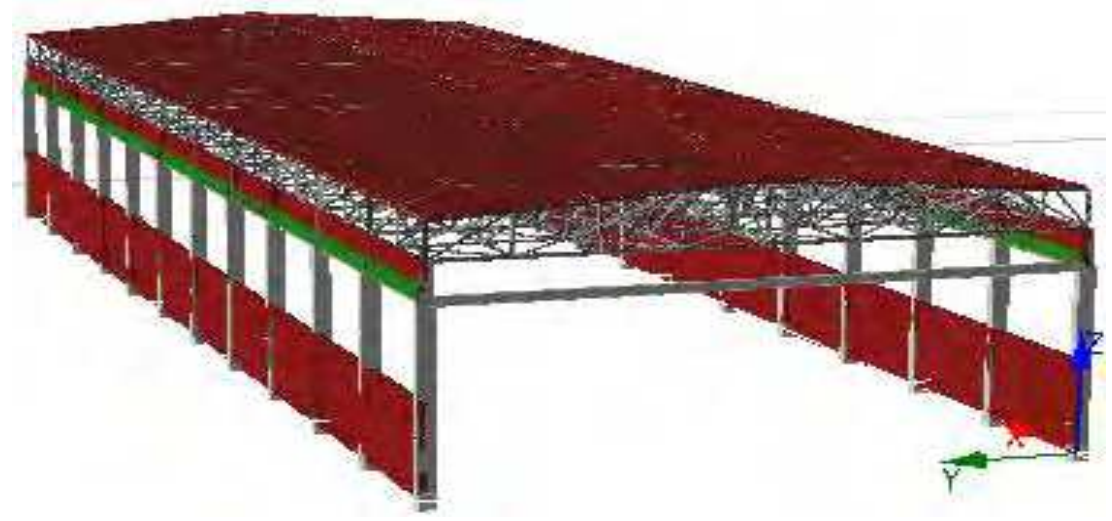

Fig. 20. The full design of the typical industrial buildings in China

The building's wall between columns generally consist of load-bearing infill masonry walls commonly made of clay bricks in Sichuan district of western China, confined by reinforced concrete vertical columns and width and thickness of wall are changed from $0.24 \mathrm{~m}$ to $0.37 \mathrm{~m}$ according China masonry code. Columns must have four $24 \mathrm{~mm}$ and $28 \mathrm{~mm}$ diameter longitudinal reinforcements, $8 \mathrm{~mm}$ diameter stirrups must be spaced $100 \mathrm{~mm}$ apart at the extremes and $200 \mathrm{~mm}$ at the centre of the elements. The stress method used for the design is according to China code.
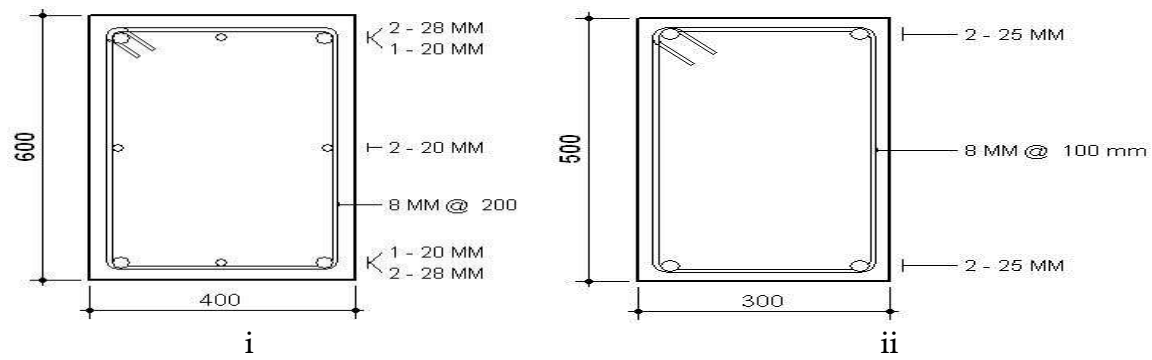

Fig. 21. RC industrial buildings' section (i: column ii: beam)

The industrial building was designed according to the China code for design of structure load for both gravity and seismic loads. The gravity load scenario consists of dead load and live load. When calculating the dead load, the weight of the structural members and the masonry infill walls was included. The roof live load used was $0.5 \mathrm{kN} / \mathrm{m}^{2}$, which is typical for an industrial building. Other types of loading, such as wind and snow, were not considered. At the same time lifting capacity of crane is considered randomly from 22 to 66 ton base on crane span and working condition. 


\subsection{Material and member property}

Because of moist climate in Sichuan district all of year, the clay brick strength must at least MU15 and the mortar strength must at least M10 according to China masonry code, so typical masonry shear strength is $0.27-1 \mathrm{Mpa}$. Bilinear stress-strain relationships with strain hardening were used for reinforced members which yield strength is $200 \mathrm{Mpa}$ and $300 \mathrm{Mpa}$, concrete strength is $30 \mathrm{Mpa}$ in considering of that many industrial buildings in Sichuan district have been built two decades ago, some respective buildings among those built even without any consideration of horizontal seismic loads. And coefficient of variation of $30 \%$ have been considered for steel and concrete respectively. Uniaxial nonlinear constant confinement concrete model that constant confining pressure is assumed throughout the entire stress-strain range is proposed by (Madas,1992) to apply to element of concrete.

\subsection{Generation of ground stochastic motion input}

Ground motion characteristics have a significant effect on the fragility curves and special attention is required during the record selection phase. Considering this fact, 90 corrected stochastic artificial ground motions have been used in this study from different PGA covering a wide range of characteristics with a magnitude range between 5.1 and 7.8 . The motions are generally recorded on soft to medium sites according to Sichuan region's circumstance where basis prominent period range from $0.35 \mathrm{~s}$ to $0.45 \mathrm{~s}$ according China seismic code and crossed over the foundation in random orientation within $\mathrm{x}$-direction or $\mathrm{y}$ direction or both direction. as shown in Fig.11.

\subsection{Damage level definition}

The aim of this analysis is to evaluate the building's potential seismic performance, establishing a relation between the intensity of the seismic action and different damage states up to collapse. so damage level is defined according to the cracking, yielding or collapse of a set of elements or connections in the structure, as presented following Table.8.

Four limit state conditions have been taken into account: light damage, moderate damage, extensive damage and complete damage as table1 So if a building deforms beyond the extensive damage limit state it might not be economically advantageous to repair the building because many of the industrial buildings of Sichuan region were be set up without carefully thought of structural seismic codes of China.

\begin{tabular}{|c|c|c|}
\hline Limit state & Inter-story drift $(\mathrm{mm})$ & ISD ratio(\%) \\
\hline Light damage & 24 & 0.25 \\
Moderate damage & 38.5 & 0.40 \\
Extensive damage & 96.0 & 1.00 \\
Collapse & 240 & 2.50 \\
\hline
\end{tabular}

Table 8. Limit States and corresponding inter-story drifts ratios (ISD\%)

\subsection{Fragility curve}

Dynamic time-history analysis is used to evaluate the seismic response and to derive the fragility curve. This approach is the most tedious but it is also the more direct and accurate way to assess the fragility of Sichuan industrial buildings. The selected frame with confined 
masonry shear wall was subject to each group of the stochastic artificial records. Each group records were consisted of three stochastic ground motions.

There have some peak-displacement-history of original frame to be shown in Fig.22.
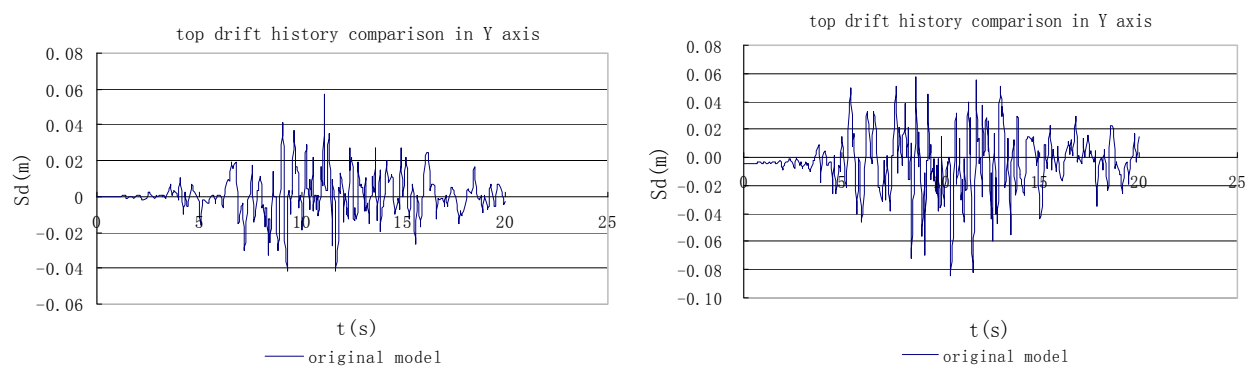

Fig. 22. Top drift time history with pga $=300$ gal in $X$ and $Y$ direction

The damage versus motion relationship is illustrated in Fig.23, The damage axis (Y-axis) described in terms of maximum inter storey drift ratio $\left(\mathrm{ISD}_{\max } \%\right)$ when the hazard axis $(\mathrm{X}$ axis) is described as spectral acceleration (Sa). Each vertical line of scattered data corresponds to an intensity level. From bottom to top, these are four limit states as light damage to complete damage respectively. Moreover the average value of each vertical data are connect by red line when \pm 0.3 variance have been considered as brown lines. The results also revealed that difference of seismic capacity of structure at two directions of industrial buildings, a standard deviation fit is assumed as 0.3.

The probability of exceedance of a certain limit state is obtained by calculating the area of the standard normal distribution over the horizontal line of that limit state.
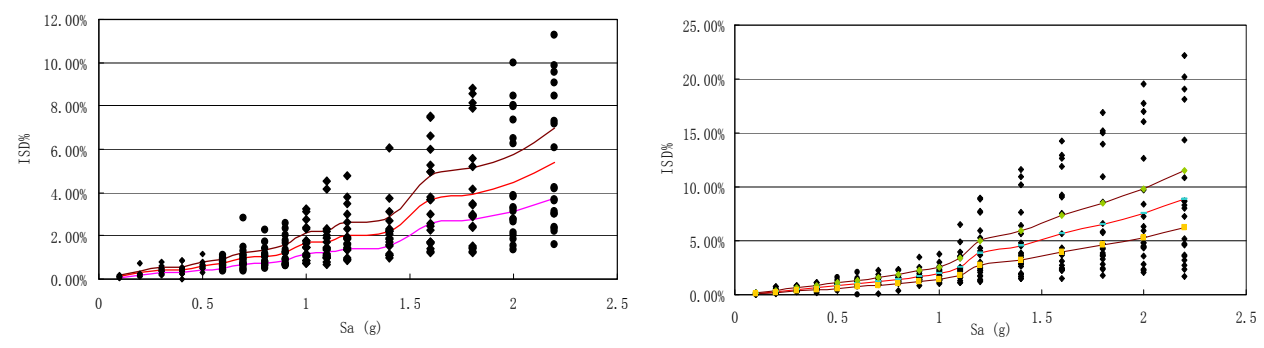

Fig. 23. Damage versus motion relationship in $X$ and $Y$ direction

After calculating the probability of exceedance of the limit state for each intensity level, the vulnerability curve can be constructed by plotting the calculated data versus Sa.

Fig.24 represents the fragility curves of typical industrial buildings in Western China with different spectral characteristic parameter. The curves become flatter as the nature of the statistical distribution of the response data. Vertical curves would represent deterministic response. 


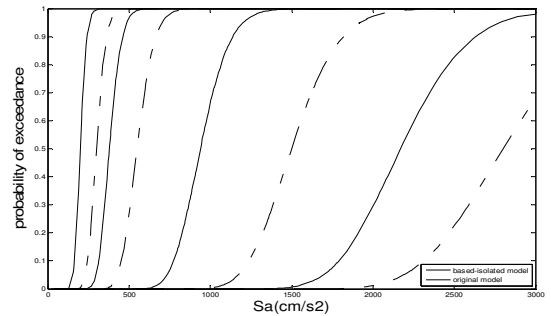

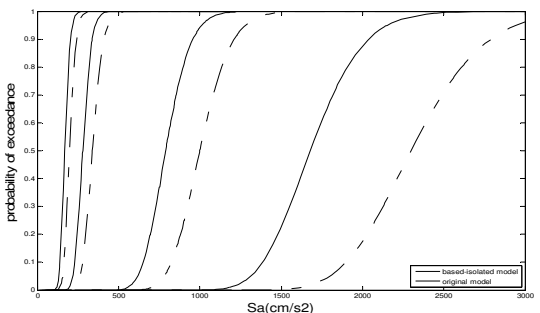

ii

Fig. 24. Vulnerability curve with spectral acceleration (i : X direction; ii: Y direction)

\section{Conclusion}

The following conclusions have been obtained.

1. The seismic vulnerability research is actual important part of perform based seismic design (PBSD), and the research work is inevitably lasting along perform based seismic design theory. The representative response spectrum of West China was been built and fit unsteady initial stochastic record in consideration of characteristic of frequency and random angle of phase position. The actual applied stochastic wave was been created after initial wave optimized with China code spectrum.

2. The representative small high-rise RC-shear wall buildings were been selected and seismic vulnerability analysis been made based dynamic time-history method, the analytical vulnerability curves were been obtained firstly in homeland. Probability of moderate damage was much seldom when PGA $<0.1 \mathrm{~g}$ under foundation stability precondition, in contrary probability of moderate damage was started to increasing when PGA $>0.3 \mathrm{~g}$. The seismic capability of longitudinal and transversal orientation of small high-rise RC-shear wall buildings was different, probability of slight damage was coherent under minor earthquake, vulnerability of longitudinal orientation ( $X$ axis) was less than transverse orientation ( $Y$ axis) of frame under major earthquake obviously.

3. The typical MIRS in China were been modeled and their seismic fragility characteristic were studied on the base of dynamic nonlinear method. The results display better response features than general type of RC frames. The steep light damage curve reflects the roles of the infill brick panels that dominate the response in the vicinity of the light damage limit state. When the confined infill column are damaged and laminated rubber bearings began to play a key role in seicmic energy dissipation, the building reach interstory drift more flexible than before.

4. The seismic performance and vulnerability of industrial buildings were also been analyzed, seismic capacity and vulnerability of based-isolated models and original models were been compared. The seismic capability of two orientations was also different and longitudinal orientation of industrial buildings ( $X$ axis) was more capacity in seismic resistance than transverse orientation ( $\mathrm{Y}$ axis) of buildings. Based-isolated model minimized $30 \%-50 \%$ of $\mathrm{ISD}_{\max } \%$ comparing to original model under major earthquake, so the based-isolated industrial buildings are more high seismic resistance than original industrial buildings in major earthquake. 


\section{Acknowledgement}

The author was funded by the State key Program of National Natural Science Foundation of China (Grant No. 90815027), National Natural Science Foundation of China (Grant No. 51078097) and Natural Science Foundation of Ningxia Province (Grant No. NZ1156).

\section{References}

I. Takewaki (2011). Preliminary report of the 2011 off the Pacific coast of Tohoku Earthquake. Journal of Zhejiang Univ-Sci A (Appl Phys \& Eng), Vol.12, No.5, pp. (327334), ISSN: 1862-1775

Whitman, R.V.; Reed, J.W. and Hong, S.T. (1973). Earthquake Damage Probability Matrices, Proceedings of the Fifth World Conference on Earthquake Engineering, Rome, Italy, 12,1973.

Braga, F.; Dolce, M. and Liberatore, D.A. (1982). Statistical Study on Damaged Buildings and an Ensuing Review of the MSK-76 Scale. Proceedings of the Seventh European Conference on Earthquake Engineering. Athens, Greece.1982.

Corsanego, A. \& Petrini, V. (1990). Seismic Vulnerability of Buildings - Work in Progress. Proceedings of the Workshop II on Seismic Risk Vulnerability and Risk Assessment, Trieste, Italy, 1990.

Di Pasquale, G.; Orsini, G. and Romeo, R.W. (2005). New Developments in Seismic Risk Assessment in Italy, Bulletin of Earthquake Engineering, Vol. 3, No. 1, (2005), pp. (101128), ISSN:1573-1456

Dolce, M.; Masi, A.; Marino, M. and Vona, M. (2003). Earthquake Damage Scenarios of the Building Stock of Potenza (Southern Italy) Including Site Effects, Bulletin of Earthquake Engineering, Vol. 1, No. 1, (2003), pp.(115-140), ISSN:1573-1456

Grünthal, G. (editor) (1998). Cahiers du Centre Européen de Géodynamique et de Séismologie: Volume 15 - European Macroseismic Scale 1998, European Center for Geodynamics and Seismology, ISBN : 2-87977-008-4,Luxembourg.

Yamazaki, F. \& Murao, O. (2000). Vulnerability functions for Japanese buildings based on damage data from the 1995 Kobe earthquake. Implication of recent earthquakes on seismic risk: Series on Innovation and Construction, Vol. 2, Imperial College Press, ISBN: 978-186094-233-4, London

Orsini, G. (1999). A Model for Buildings' Vulnerability Assessment Using the Parameterless Scale of Seismic Intensity (PSI). Earthquake Spectra, Vol. 15, No. 3, (1999), pp. (463483), ISSN: 8755-2930

M. A. Erberik \& Amr S. Elnashai. (2004). Fragilityanaly sis of flat-slab structures. Engineering Structures, Vol.26, pp. (937-948), ISSN: 0141-0296

T. Rossetto \& Amr Elnashai. (2005).A new analytical procedure for the derivation of displacement-based vulnerability curves for populations of RC structures. Engineer Structures, Vol.27, pp.(397-409), ISSN: 0141-0296

M. S. Kircil \& Z. Polat. (2006), Fragility analysis of mid-rise R/C frame buildings. Engineering Structures, Vol.28, pp.(1335-1345), ISSN: 0141-0296

Jun Ji ; Amr S. \& Elnashai. (2007). Daniel A. Kuchma, An analytical framework for seismic fragility analysis of RC high-rise buildings. Engineering Structures, Vol.29, pp.(31973209), ISSN: 0141-0296 
B. Borzi.; R. Pinho \& H. Crowley.(2008). Simplified pushover-based vulnerability analysis for large-scale assessment of RC buildings. Engineer Structures, Vol.30, pp.(804-820), ISSN: 0141-0296

Kaul, M.K. (1978). Stochastic Characterization of Earthquake through Their Response Spectrum. Earthquake Engineering and Structural Dynamics, Vol.6, No.5, pp.(497-509), ISSN: 0098-8847

Murphy JR \& O'Brien LJ. (1977).The correlation of peak ground acceleration amplitude with seismic intensity and other physical parameters. Bull Seismol Soc Am, Vol.67,pp.(877-915), ISSN: 0037-1106

Husid,R.L. (1969)Analisis de Terremotos: Analisis General, Revista de IDlEM. Santiago Chile, Vol.8, No.1,pp.(21-42), ISSN:0716-1832

Trifunacc,M.D \& Brady,A.G. (1975). On the Correlation of Peak Accelaration of Strong Motion with Earthquake Magnitude Epicentral Distance and Site Condition Proc.US Nat.Conf. Earthquake Engineering, pp.(43-52), ISSN: 1570-761X

Takizawa,H.et.al. (1980).Collapse of a Modal for Ductile Reinforced Concrete Frames under Extreme Earthquake Motion. EESD, Vol.8, No.2, ISSN: 1521-334X

Jennings PC. \& Housner GW. (1968). Tsai NC Simulated earthquake motions. Technical Report. Earthquake Engineering Research Laboratory, California Institute of Technology

Ministry of Construction P.R. China.(2002). Code for seismic design of buildings (GB500112001). Beijing: China Construction Press

China Association for Engineer construction standardization.(2001).Technical specification for seismic-isolation with laminated rubber beating isolators CECS126:2001. Beijing: China Construction Press.

Banon,H. \& Veneziano,D. (1982). Seismic Safety of Reinforced Concrete Members and Structures. Earthquake Engineering and Structural Dynamics, Vol.10, pp.(179-193), ISSN: 0098-8847

Park, Y.J. \& Ang, A.H.S. (1985). Mechanistic Seismic Damage Model for Reinforced Concrete. Journal of Structural Engineering, Vol. 111, No. 4, pp.(722-739), ISSN: 09700137

Colombo,A \& Negro,P. (2005). A damage index of generalised applicability. Engineer Structures, Vol.27, pp.(1164-1174), ISSN: 0141-0296

Madas, P. and Elnashai, A.S. (1992). A new passive confinement model for transient analysis of reinforced concrete structures. Earthquake Engineering and Structural Dynamics, Vol. 21, pp. (409-431), ISSN: 0098-8847

Martinez-Rueda, J.E. \& Elnashai, A.S. (1997). Confined concrete model under cyclic load. Materials and Structures, Vol. 30, No. 197, pp. (139-147), ISSN: 1359-5997

Menegotto, M., Pinto, P.E. (1973). Method of analysis for cyclically loaded RC plane frames including changes in geometry and non-elastic behaviour of elements under combined normal force and bending, Symposium on the Resistance and Ultimate Deformability of Structures Acted on by well defined Repeated Loads, International Association for Bridge and Structural Engineering, Zurich, Switzerland, pp. (15-22)

Filippou, F.C.\& Popov, E.P., Bertero, V.V. (1983) Modelling of R/C joints under cyclic excitations, ASCE Journal of Structural Engineering, Vol. 109, No. 11, pp. (2666-2684), ISSN: 0970-0137 
Monti, G. \& Nuti, C. (1992). Nonlinear cyclic behaviour of reinforcing bars including buckling, Journal of Structural Engineering, Vol. 118, No. 12, pp.(3268-3284), ISSN: 0970-0137

Prota, A., Cicco, F., Cosenza, E.(2009). Cyclic behavior of smooth steel reinforcing bars: experimental analysis and modeling issues, Journal of Earthquake Engineering, Vol. 13, No. 4, pp.(500-519), ISSN: 1363-2469

A. Ghobarah (1999). Response-based Damage Assessment of Structures, Earthquake Engineering and Structural Dynamics, Vol. 28, No. 1, pp.(79-104), ISSN: 1096-9845

Casarotti, C; Pinho, R \& Calvi, GM.(2005). Adaptive pushover-based methods for seismic assessment and design of bridge structures, ROSE Research Report 2005/06. Pavia, Italy: IUSS Press, ISBN: 0-646-00004-7

Ohsaki, Y.(1978). On the significance of Phase Content in Earthquake Ground Motions. Earthquake Engineering and Structural Dynamics, Vol. 7, No.5, ISSN: 0098-8847

Amin, M. \& Ang, A. S. (1968). Non-stationary Stochastic Model of Earthquake Motions. Journal of American Society of Civil Engineers, Vol.94, No.EM2, ISSN: 1090-0241

A.Moustafa (2011). Damage-Based Design Earthquake Loads for Single-Degree-Of -Freedom Inelastic Structures. Journal of structural engineering (ASCE), Vol.137, No.3, pp. (456467), ISSN: 0733-9445 


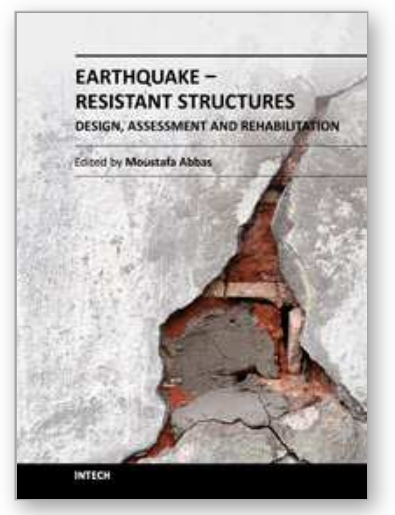

\section{Earthquake-Resistant Structures - Design, Assessment and Rehabilitation}

Edited by Prof. Abbas Moustafa

ISBN 978-953-51-0123-9

Hard cover, 524 pages

Publisher InTech

Published online 29, February, 2012

Published in print edition February, 2012

This book deals with earthquake-resistant structures, such as, buildings, bridges and liquid storage tanks. It contains twenty chapters covering several interesting research topics written by researchers and experts in the field of earthquake engineering. The book covers seismic-resistance design of masonry and reinforced concrete structures to be constructed as well as safety assessment, strengthening and rehabilitation of existing structures against earthquake loads. It also includes three chapters on electromagnetic sensing techniques for health assessment of structures, post earthquake assessment of steel buildings in fire environment and response of underground pipes to blast loads. The book provides the state-of-the-art on recent progress in earthquake-resistant structures. It should be useful to graduate students, researchers and practicing structural engineers.

\section{How to reference}

In order to correctly reference this scholarly work, feel free to copy and paste the following:

Zhu Jian (2012). Seismic Vulnerability Analysis of RC Buildings in Western China, Earthquake-Resistant Structures - Design, Assessment and Rehabilitation, Prof. Abbas Moustafa (Ed.), ISBN: 978-953-51-0123-9, InTech, Available from: http://www.intechopen.com/books/earthquake-resistant-structures-design-assessmentand-rehabilitation/seismic-vulnerability-of-rc-buildings-in-western-china

\section{INTECH}

open science | open minds

\author{
InTech Europe \\ University Campus STeP Ri \\ Slavka Krautzeka 83/A \\ 51000 Rijeka, Croatia \\ Phone: +385 (51) 770447 \\ Fax: +385 (51) 686166 \\ www.intechopen.com
}

\author{
InTech China \\ Unit 405, Office Block, Hotel Equatorial Shanghai \\ No.65, Yan An Road (West), Shanghai, 200040, China \\ 中国上海市延安西路65号上海国际贵都大饭店办公楼 405 单元 \\ Phone: +86-21-62489820 \\ Fax: +86-21-62489821
}


(C) 2012 The Author(s). Licensee IntechOpen. This is an open access article distributed under the terms of the Creative Commons Attribution 3.0 License, which permits unrestricted use, distribution, and reproduction in any medium, provided the original work is properly cited. 